\title{
ANALISIS FAKTOR - FAKTOR YANG MEMPENGARUHI KEPUTUSAN BERKUNJUNG PADA MAKAM SYECH QURO KARAWANG
}

\author{
Abdul Yusuf,SE.,MM. Nia Darnia \\ Program Studi Manajemen, Fakultas Ekonomi dan Bisnis, Universitas \\ Singaperbangsa Karawang Jl. H.S Ronggowaluyo Teluk Jambe Karawang 41361 \\ Email: abdul.yusuf@fe.unsika.ac.id
}

\begin{abstract}
Abstak : Penelitian ini membahas faktor apa saja yang mempengaruhi keputusan berkunjung pada makam Syech Quro Karawang dan faktor apa yang dominan mempengaruhi keputusan berkunjung pada makam Syech Quro Karawang. Sampel penelitian ini adalah 307 orang pengunjung makam Syech Quro Karawang. Hasil penelitian ini menunjukan bahwa faktor-faktor yang mempengaruhi keputusan berkunjung pada makam Syech Quro Karawang adalah faktor keinginan untuk menambah pengetahuan baru, faktor melepaskan diri dari rutinitas pekerjaan, faktor menjalin silahturami dan faktor ingin menikmati aktivitas yang menyenangkan, dan faktor dominan yang mempengaruhi keputusan berkunjung pada makam Syech Quro Karawang adalah faktor keinginan untuk menambah pengetahuan baru.
\end{abstract}

Kata Kunci : Keputusan Berkunjung, Melepaskan Diri, Relaksasi, Bermain, Mempererat Ikatan Keluarga, Gengsi, Interaksi Sosial, Romantis, Peluang Pendidikan, Pemenuhan Diri, dan Harapan Terpenuhi

Abstract : This study discusses what factors influence the decision to visit the tomb of Syech Quro Karawang and what factors predominantly influence the decision to visit the tomb of Syech Quro Karawang. The sample of this study was 307 visitors to the tomb of Syech Quro Karawang. The results of this study indicate that the factors that influence the decision to visit the tomb of Syech Quro Karawang are the factors of wanting to add new knowledge, the factor of breaking away from work routines, the factor of strengthening family bonds and the factor of wanting to enjoy pleasant activities, and the dominant factor influencing the decision of visiting the tomb of Syech Quro Karawang is a factor in wanting to add new knowledge.

Keywords: Visiting Decision, Exscape, Relaxation, Play, Strengthening Family bonds , Prestige, Social Interaction, Romance, Educational Opportunities, Self-Fulfillment, and Wish Fulfillment.

\section{PENDAHULUAN}

Indonesia memiliki potensi pariwisata mulai dari bentukan alam secara alami, keadaan sosial yang beragam seperti budaya, suku dan adat istiadat yang dapat dijadikan sebagai aktivitas pariwisata. Hal tersebut dikarenakan pariwisata adalah suatu proses pembangunan yang dilakukan untuk mengembangkan potensi-potensi Indonesia yang mengandung aspek sosial budaya, ekonomi dan politik.

Perjalanan yang dilakukan oleh seseorang dipengaruhi oleh faktor dari dalam diri sendiri (faktor internal) seperti kesehatan, pendidikan, keuangan, dan faktor dari luar (faktor eksternal) seperti iklim, letak geografis, special event, dan lain sebagainya.

Jawa Barat merupakan salah satu proivnsi yang mempunyai banyak potensi dalam bidang wisata. Masyarakat Jawa
Barat yang masih menjalankan tradisitradisi budaya luhur sebagai masyarakat yang patuh pada ajaran agama/ agamis, yang mempunyai kekayaan warisan budaya dan nilai-nilai luhur tradisional, memiliki prilaku sosial yang berfalsafah pada silih asih, silih asah, silih asuh, yang berarti saling mengasihi, saling memberi pengetahuan dan saling mengasuh diantara warga masyarakat. Dan masih sangat menjaga nilai- nilai budaya tradisional berdasarkan turun-temurun. 


\section{Tabel 1}

Jumlah Wisatawan Yang Datang Ke Objek Wisata di Provinsi Jawa Barat

\begin{tabular}{|c|c|c|c|}
\hline Tahun & $\begin{array}{c}\text { Wisatawan } \\
\text { Nusantara }\end{array}$ & $\begin{array}{c}\text { Wisatawan } \\
\text { Mancanegara }\end{array}$ & Total \\
\hline 2013 & 31.702 .138 & 916.533 & 32.618 .671 \\
\hline 2014 & 33.617 .999 & 1.059 .904 & 34.677 .903 \\
\hline 2015 & 38.286 .230 & 1.287 .554 & 39.573 .784 \\
\hline 2016 & 39.195 .688 & 2.673 .379 & 43.703 .778 \\
\hline 2017 & 42.406 .484 & 2.945 .716 & 45.352 .200 \\
\hline
\end{tabular}

Sumber : Dinas Pariwisata Provinsi Jawa Barat 2017

Karawang merupakan salah satu kabupaten yang terletak di Jawa Barat. Karawang memiliki keragaman pemandangan alam, seni dan budaya, serta adat istiadat. Oleh karena itu, di Karawang terdapat banyak tempat wisata baik itu wisata rekreasi, alam, pantai, religi dan seni budaya.

Makam Syekh Quro, Klenteng Sian Ji Ku Po, Komplek Makam Mantan Bupati Karawang. Dari ketiga lokasi tersebut lokasi yang paling banyak dikunjungi adalah Makam Syekh Quro Karawang dimana lokasi tersebut merupakan tempat yang bersejarah dalam menyebarkan agama Islam, dan lokasi tersebut juga merupakan lokasi ditemukanya guru besar yaitu syekh Hasanudin atau yang biasa kita kenal dengan sebutan Syekh Quro ,beliu adalah seorang Hafiz Qur'an dan beliu lah yang menyebarkan ajaran agama islam di Karawang.

Banyaknya pengunjung yang datang ke tempat tersebut bisa kita lihat pada Grapik berikut :

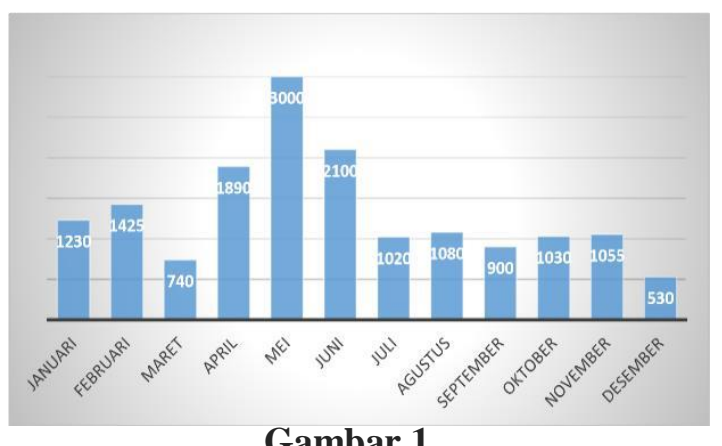

Gambar 1

Data Pengunjung Makam Syech Quro Karawang

Sumber : Data diolah peneliti, 2019
Berdasarkan data tersebut kita bisa mengetahui bahwa tingkat kunjungan yang datang ke makam syekh quro tersebut mengalami fluktuktuasi dan terlihat signifikan meningkat pada bulan mei dan juni pada tahun 2018.

Penelitian mengenai wisata religi juga pernah dilakukan oleh Tus Ria Nurmalasari dengan journl yang berjudul "Analisis Faktor Yang Mempengaruhi Pengunjung Objek Wisata Kawah Ijen Banyuwangi".Dimana dalam penenlitian memperoleh hasil yaitu : Faktor-faktor yang mempengaruhi proses pengambilan keputusan Objek Wisata Kawah Ijen Banyuwangi berdasarkan teori Pitana dan Gayatri (2011:73) terdiri dari sub-variable sebagai berikut : escape, relaxtation, play, strengthening family bonds, prestige, social interaction, romance, educational opportunjity, self-fufillmen dan wishfullfillment. Berdasarkan latar belakang masalah diatas maka penulis tertarik untuk membahas lebih lanjut mengenai "Analisis Faktor-Faktor yang Mempengaruhi Keputusan Berkunjung pada Makam Syech Quro Karawang.

\section{LANDASAN TEORI}

\section{Keputusan Berkunjung}

Menurut Schiffman dan Kanuk (2015:3) keputusan merupakan seleksi atas dua atau lebih dari alternatif yang ada. Dalam hal ini, pilihan alternatif harus tersedia ketika proses penentuan keputusan dilakukan. Pilihan alternatif digunakan sebagai perbandingan atau acuan ketika keputusan akan ditentukan.

Kotler dan Amstrong (2015:3) mendefinisikan keputusan berkunjung sebagai aktifitas konsumen dimana membeli atau menggunakan jasa yang paling disukai.

\section{Pariwisata}

Menurut Undang-Undang No.10 Tahun (2009:9) mengatakan bahwa pariwisata adalah berbagai macam kegiatan wisata dan didukung beerbagai fasilitas serta layanan yang disediakan oleh masyarakat, pengusaha, pemerintah dan pemerintah daerah.

Sedangkan WTO (dalam muljadi 2009:9) mengatakan bahwa pariwisata 
sebagai berbagai aktivitas yang dilakukan orang-orang yang mengadakan perjalanan untuk dan tinggal diluar kebiasaan lingkunganya dan tidak lebih dari satu tahun berturut-turut untuk kesenangan, bisnis, dan keperluan lain.

\section{Faktor - Faktor Yang Mempengaruhi Keputusan Berkunjung}

Pitana dan Gayatri (2011:26) mengemukakan faktor yang mempengaruhi seseorang untuk melakukan perjalanan wisata antara lain:

\section{1) Escape}

Ingin melepaskan diri dari lingkungan yang dirasakan menjemukan, atau kejenuhan dari pekerjaan sehari-hari.

\section{2) Relaxation}

Keinginan untuk penyegaran, yang berhubungan dengan motivasi untuk escape.

\section{3) Play}

Ingin menikmati kegembiraan, melalui berbagai permainan yang merupakan pemunculan kembali dari sifat kekanakkanakan dan melepaskan diri sejenak dari berbagai urusan yang serius.

\section{4) Strengthening family bonds}

Ingin menjalin hubungan keakraban dengan kerabat, khususnya dalam konteks VFR (Visiting Friends and Relations). Keakraban hubungan kekerabatan ini bisa dilihat diantara anggota keluarga yang melakukan perjalanan bersama-sama.

\section{5) Prestige}

Untuk menunjukan gengsi dengan mengunjungi destinasi yang menunjukan kelas dan gaya hidup yang juga merupakan dorongan untuk meningkatkan status sosial.

\section{6) Social interaction}

Untuk dapat melakukan interaksi sosial dengan teman sejawat atau masyarakat lokal yang dikunjungi.

\section{7) Romance}

Keinginan untuk bertemu dengan orang-orang yang biasa memberikan suasana romantis.

\section{8) Educational opportunity}

Keinginan untuk melihat sesuatu yang baru, mempelajari orang lain.

\section{9) Self-fullfilment}

Keinginan untuk menemukan diri sendiri karena biasanya bisa ditemukan pada saat kita menemukan daerah baru.

\section{0) Wish-fulfilment}

Keinginan untuk merealisasikan mimpimimpi yang lama dicitacitakan, sampai mengorbankan diri dengan cara berhemat agar bisa melakukan perjalanan.

\section{METODE PENELITIAN \\ POPULASI}

Populasi menurut Sugiyono (2017:80) menjelaskan bahwa: populasi adalah wilayah generalisasi yang terdiri atas : objek/subjek yang mempunyai kualitas dan karakteristik tertentu yang ditetapkan oleh peneliti untuk dipelajari dan kemudian ditarik kesimpulannya. Populasi dalam penelitian ini adalah seluruh pengunjung makam Syech Quro Karawang selama tahun 2018 yaitu sebanyak 16.000 orang.

\section{SAMPEL}

Menurut Sugiyono (2016:81) sampel adalah sebagian dari populasi itu. Populasi bisa diartikan sebagai masyarakat didaerah tertentu, jumlah pekerja pada suatu perusahaan atau organisasi, jumlah pengajar dan murid di sekolah dan lainnya. Populasi pengunjung Makam Syekh Quro sebanyak 307 orang.

\section{DEFINISI OPERASIONAL}

\section{1) Escape}

Ingin melepaskan diri dari lingkungan yang dirasakan menjenuhkan, atau kejenuhan dari pekerjaan sehari-hari.

\section{2) Relaxation}

Keinginan untuk penyegaran, yang berhubungan dengan motivasi untukescape.

\section{3) Play}

Ingin menikmati kegembiraan, melalui berbagai permainan yang merupakan pemunculan kembali dari sifat kekanak- 
kanakan dan melepaskan diri sejenak dari berbagai urusan yang serius.

\section{4) Strengthening family bonds}

Ingin mempererat hubungan

kekerabatan bersama seseorang terdekat, khususnya dalam konteks VFR (Visiting Friends and Relations) . Keakraban kekerabatan diantara keluarga ini juga terjadi diantara anggota keluarga yang melakukan perjalanan bersama-sama.

\section{5) Prestige}

Untuk menunjukan gengsi dengan mengunjungi destinasi yang menunjukan kelas dan gaya hidup yang juga merupakan dorongan untuk meningkatkan status sosial.

\section{6) Social interaction}

Untuk dapat melakukan interaksi sosial dengan teman sejawat atau masyarakat lokal yang dikunjungi.

\section{7) Romance}

Keinginan untuk bertemu dengan orang-orang yang biasa memberikan suasana romantis.

\section{8) Educational opportunity}

Keinginan untuk melihat sesuatu yang baru, mempelajari orang lain.

\section{9) Self-fullfilment}

Keinginan untuk menemukan diri sendiri karena biasanya bisa ditemukan pada saat kita menemukan daerah baru.

\section{0) Wish-fulfilment}

Keinginan untuk merealisasikan mimpimimpi yang lama dicitacitakan, sampai mengorbankan diri dengan cara berhemat agar bisa melakukan perjalanan.

\section{TEKNIK ANALISIS DATA}

\section{Analisis Deskriptif}

Analisis deskriptif adalah suatu metode pengumpulan untuk memperoleh bahan-bahan teoritis yang dapat dijadikan dasar bagi pengkaji masalah. Penelitian ini menggunakan rentang skala untuk menentukan hasil tanggapan dari responden

\section{Analisis Faktor}

Analisis faktor adalah sebuah model, dimana tidak terdapat variabel bebas dan tergantung. Analisis faktor tidak mengklasifikasikan variabel ke dalam kategori variabel bebas dan tergantung melainkan mencari hubungan interdependensi antar variabel agar dapat mengidentifikasikan dimensi-dimensi atau faktor-faktor yang menyusunya. Pada analisis faktor, terdapat 6 tahap yaitu: masalah penelitian, matriks korelasi, ekstraksi faktor, matriks faktor sebelum dan sesudah dirotasi dan menentukan bobot faktor.

\section{ANALISIS DAN PEMBAHASAN}

Profil Responden

Tabel 2

Profil Responden

\begin{tabular}{|c|c|c|c|}
\hline $\begin{array}{c}\text { Data } \\
\text { Deskriptif }\end{array}$ & Keterangan & Frekuensi & Presentase \\
\hline \multirow{2}{*}{$\begin{array}{c}\text { Jenis } \\
\text { Kelamin }\end{array}$} & Pria & $\underline{147}$ & $14,9 \%$ \\
\hline & Wanita & 160 & $52,1 \%$ \\
\hline \multirow[t]{5}{*}{ Usia } & 17-20 tahun & 136 & $44,2 \%$ \\
\hline & 21-25 tahun & 45 & $14,6 \%$ \\
\hline & 26-30 tahun & 68 & $22,1 \%$ \\
\hline & 31-35 tahun & 52 & $16,9 \%$ \\
\hline & $>35$ & 6 & $2,2 \%$ \\
\hline \multirow[t]{7}{*}{ Pendidikan } & SD & 11 & $3,58 \%$ \\
\hline & SMP & 98 & $31,9 \%$ \\
\hline & SMA & 144 & $46,9 \%$ \\
\hline & D3 & 6 & $1,95 \%$ \\
\hline & S1 & 28 & $9,12 \%$ \\
\hline & S2 & 3 & $1,02 \%$ \\
\hline & Lainnya & 17 & $5,53 \%$ \\
\hline \multirow[t]{7}{*}{ Pekerjaan } & Pelajar & 33 & $10,7 \%$ \\
\hline & Mahasiswa & 37 & $12,0 \%$ \\
\hline & $\begin{array}{l}\text { Karyawan } \\
\text { Swasta }\end{array}$ & 75 & $24,4 \%$ \\
\hline & PNS & 11 & $3,58 \%$ \\
\hline & Wiraswasta & 57 & $18,5 \%$ \\
\hline & Petani & 30 & $10,02 \%$ \\
\hline & Lainnya & 64 & $20,8 \%$ \\
\hline \multirow[t]{4}{*}{ Penghasilan } & $<1.000 .000$ & 78 & $25,4 \%$ \\
\hline & $\begin{array}{l}\text { Rp.1.000.000 - } \\
\text { Rp.3.000.000 }\end{array}$ & 115 & $37,4 \%$ \\
\hline & $\begin{array}{l}\text { Rp.3.000.000 - } \\
\text { Rp.5.000.000 }\end{array}$ & 96 & $31,2 \%$ \\
\hline & $>5.000 .000$ & 18 & $6 \%$ \\
\hline
\end{tabular}




\begin{tabular}{|c|c|c|c|}
\hline \multicolumn{2}{|c|}{$\begin{array}{l}\text { Tabel } 2 \text { (Lanjutan) } \\
\text { Profil Responden }\end{array}$} & & $\begin{array}{l}\text { berkunjung pada Makam Syekh Quro } \\
\text { Karawang.. }\end{array}$ \\
\hline $\begin{array}{c}\text { Data } \\
\text { Deskriptif }\end{array}$ & Keterangan & Frekuensi & $\begin{array}{l}\text { Presentáseiabel yang dipergunakan sudah } \\
\text { dispesifikasikan berdasarkan penelitian }\end{array}$ \\
\hline \multirow{4}{*}{$\begin{array}{l}\text { Informasi } \\
\text { lokasi }\end{array}$} & Masyarakat & 152 & $49,5 \%$ sebelumnya, teori, dan pertimbangan dari \\
\hline & Teman/keluarga & 126 & $41,0 \%$ peneliti. \\
\hline & Internet & 15 & $4,78 \%$ Peng kuran variabel berdasarkan skala \\
\hline & Lainnya & 14 & $4,72 \%$ liker $1-5$. \\
\hline \multirow{4}{*}{$\begin{array}{l}\text { Frekuensi } \\
\text { kunjungan }\end{array}$} & 1 kali & 130 & $42,3 \%$ Banyaknya sampel pada penelitian ini \\
\hline & $2-5$ kali & 164 & $53,4 \%$ adala 307 atau sudah memadai atau \\
\hline & 6-10 kali & 10 & $3.25 \%$ lebih dari 4 kali jumlah butir pertanyaan. \\
\hline & $>10$ kali & 3 & 1,04Fatrik Korelasi \\
\hline
\end{tabular}

Sumber : Hasil Pengolahan Data, 2019

Berdasarkan tabel 4.1 di atas dapat dilihat bahwa sebagian besar responden berdasarkan jenis kelamin yang dipilih adalah wanita dengan jumlah 160 orang dengan presentase $52,1 \%$. Adapun data deskriptif berdasarkan usia responden, bahwa sebagian besar responden berusia 1720 tahun dengan jumlah 136 orang. Selanjutnya data deskriptif responden berdasarkan pendidikan terakhir yang ditempuh responden, bahwa sebagian besar responden berpendidikan terakhir SMA dengan jumlah 144 orang. Dan adapun data deskriptif mengenai pekerjaan responden, bahwa sebagian besar responden pekerjaannya adalah karyawan swasta dengan jumlah 75 orang. Dan data deskriptif responden mengenai penghasilan, sebagian besar responden berpengahasilan sebesar Rp.1.000.000-Rp.3.000.000 dengan jumlah 115 orang. Sebagian besar responden, mengetahui lokasi wisata tersebut dari masyarakat dengan jumlah 152 orang. Sedangkan frekuensi kunjungan responden ke lokasi 2-5 kali sebanyak 164 orang.

\section{Analisis Faktor}

\section{Idetifikasi Masalah}

a. Tujuan analisis faktor dalam penelitian ini adalah untuk mengetahui faktorfaktor yang mempengaruhi minat berkunjung wisatawan pada wisata religi Makam Syekh Quro dan faktor-faktor dominan yang mempengaruhi keputusan
Tabel 3

KMO and Bartlett's Test

\begin{tabular}{|lcc|}
\hline $\begin{array}{l}\text { Kaiser-Meyer-Olkin Measure of Sampling } \\
\text { Adequacy. }\end{array}$ & .831 \\
$\begin{array}{l}\text { Bartlett's Test of } \\
\text { Sphericity }\end{array}$ & Approx. Chi-Square & \\
& & $1.451 \mathrm{E}$ \\
& Df & 3 \\
& Sig. & .000 \\
\hline
\end{tabular}

Sumber: Data diolah, 2019.

Angka KMO pada tabel di atasadalah 0,831 menunjukan bahwa hubungan korelasi antara variabel yang diuji sudah baik. Nilai KMO minimal untuk dilakukannya analisis faktor adalah 0,500, karena itulah analisis faktor untuk factor value consciousness dapat dilaksanakan. Tabel di atas juga menunjukan nilai signifikansi Barlett's sebesar 0,000 yaitu jauh berada dibawah 0,005. (Yeri dkk, 2017). Hal ini membuktikan adanya hubungan antara komponen dalam faktor ini, sehingga dapat dikatakan layak dipakai untuk digunakan dalam penelitian.

\section{Hasil Uji MSA}

Tabel 4

Measure of Sampling Adequency (MSA)

\begin{tabular}{clc}
\hline $\mathbf{Q}$ & \multicolumn{1}{c}{ Indikator } & $\begin{array}{c}\text { Nilai } \\
\text { MSA }\end{array}$ \\
\hline 1 & $\begin{array}{l}\text { Melepaskan diri dari } \\
\text { rutinitas pekerjaan }\end{array}$ & 0,739 \\
\hline 2 & melepaskan kegelisahan & 0,746 \\
\hline 3 & menyegarkan pikiran & 0,855 \\
\hline
\end{tabular}


Tabel 4 (Lanjutan)

Measure of Sampling Adequency (MSA)

\begin{tabular}{|c|c|c|}
\hline $\mathbf{Q}$ & Indikator & $\begin{array}{l}\text { Nilai } \\
\text { MSA }\end{array}$ \\
\hline 4 & mencari ketenangan & 0,821 \\
\hline 5 & $\begin{array}{l}\text { ingin menikmati aktivitas } \\
\text { yang menyenangkan }\end{array}$ & 0,855 \\
\hline 6 & $\begin{array}{lr}\text { Melakukan } & \text { kunjungan } \\
\text { untuk } & \text { mendapatkan } \\
\text { keberkahan } & \end{array}$ & 0,879 \\
\hline 7 & $\begin{array}{l}\text { mempererat hubungan } \\
\text { keakraban }\end{array}$ & 0,871 \\
\hline 8 & menjalin silaturahmi & 0,802 \\
\hline 9 & $\begin{array}{l}\text { Berkunjung ke kawasan } \\
\text { wisata untuk meningkatkan } \\
\text { status social }\end{array}$ & 0,793 \\
\hline 10 & $\begin{array}{l}\text { interaksi } \\
\text { masyarakat sekitar }\end{array}$ & 0,869 \\
\hline 11 & mencari kenyamanan & 0,862 \\
\hline 12 & $\begin{array}{l}\text { Keinginan untuk menambah } \\
\text { pengetahuan baru }\end{array}$ & 0,839 \\
\hline 13 & $\begin{array}{l}\text { Memiliki tujuan berkunjung } \\
\text { untuk berdoa }\end{array}$ & 0,857 \\
\hline 14 & $\begin{array}{l}\text { Berkunjunguntukmengetahui } \\
\text { kegiatan wisatawan }\end{array}$ & 0,875 \\
\hline 15 & $\begin{array}{l}\text { keinginan untuk melakukan } \\
\text { perjalanan wisata }\end{array}$ & 0,863 \\
\hline 16 & Adanya keyakinan dalam diri & 0,849 \\
\hline
\end{tabular}

Sumber: Hasil Pengolahan Data, 2019

Dari tabel diatas dapat diketahui bahwa 16 indikator mempunyai angka MSA diatas 0,5 dan dapat dianalisis secara keseluruhan lebih lanjut.

\section{Ekstraksi Faktor}

Cara lain memberikan penilaian terhadap kekuatan hubungan antar butir pertanyaan atau pernyataan kuisioner adalah dengan melihat varian yang dijelaskan disetiap butir lainnya maupun faktor yang ada. Pada tabel matriks Communalities terdapat kolom initial communality yaitu varian yang dijelaskan dalam satu butir oleh variabel atau butir lainnya, sedangkan extraction communality adalah varian yang dijelaskan oleh faktor yang ada.
Tabel 5

Communalities

\begin{tabular}{|c|c|c|}
\hline & Initial & Extraction \\
\hline $\begin{array}{l}\text { Melepaskan diri dari rutinitas } \\
\text { pekerjaan }\end{array}$ & 1.000 & .725 \\
\hline melepaskan kegelisahan & 1.000 & .747 \\
\hline menyegarkan pikiran & 1.000 & .564 \\
\hline mencari ketenangan & 1.000 & .382 \\
\hline $\begin{array}{c}\text { ingin menikmati aktivitas yang } \\
\text { menyenangkan }\end{array}$ & 1.000 & .578 \\
\hline $\begin{array}{l}\text { Melakukan kunjungan untuk } \\
\text { mendapatkan keberkahan }\end{array}$ & 1.000 & .478 \\
\hline $\begin{array}{l}\text { mempererat hubungan } \\
\text { keakraban }\end{array}$ & 1.000 & .660 \\
\hline menjalin silaturahmi & 1.000 & .710 \\
\hline $\begin{array}{l}\text { Berkunjung ke kawasan wisata } \\
\text { untuk meningkatkan status } \\
\text { social }\end{array}$ & 1.000 & .667 \\
\hline $\begin{array}{l}\text { interaksi dengan masyarakat } \\
\text { sekitar }\end{array}$ & 1.000 & .587 \\
\hline mencari kenyamanan & 1.000 & .275 \\
\hline $\begin{array}{l}\text { Keinginan untuk menambah } \\
\text { pengetahuan baru }\end{array}$ & 1.000 & .464 \\
\hline $\begin{array}{l}\text { Memiliki tujuan berkunjung } \\
\text { untuk berdoa }\end{array}$ & 1.000 & .533 \\
\hline $\begin{array}{l}\text { Berkunjung untuk mengetahui } \\
\text { kegiatan wisatawan }\end{array}$ & 1.000 & .523 \\
\hline $\begin{array}{l}\text { keinginan untuk melakukan } \\
\text { perjalanan wisata }\end{array}$ & 1.000 & .625 \\
\hline Adanya keyakinan dalam diri & 1.000 & .530 \\
\hline
\end{tabular}

Extraction Method: Principal Component Analysis.

Butir-butir yang nilainya $<0,3$ sesungguhnya tidak dapat disertakan dalam analisis faktor selanjutnya, artinya dapat digugurkan. Nilai yang rendah menunjukan bahwa kecilnya varian yang dapat dijelaskan 
oleh butir tersebut. (Yeri, 2017:207) Pada tabel diatas semua nilai extraction >0,3, artinya semua indikator dapat diikut sertakan pada tahap selanjutnya dan memiliki varian yang besar.

Pada tabel diatas dapat dilihat bahwa faktor melepaskan diri dari rutinitas pekerjaan memiliki nilai 0,725 ini berarti sekitar $72,5 \%$ varians bisa dijelaskan oleh faktor yang terbentuk (tabel component Matrix) demikian dengan indikatorindikator yang lainnya.

\section{Tabel 6}

Total Variance Explained

\begin{tabular}{|c|c|c|c|c|c|c|c|c|c|}
\hline \multicolumn{10}{|c|}{ Total Variance Explained } \\
\hline $\begin{array}{l}\text { Co } \\
\text { m }\end{array}$ & \multicolumn{3}{|c|}{ Initial Eigenvalues } & \multicolumn{3}{|c|}{$\begin{array}{l}\text { Extraction Sums of } \\
\text { Squared Loadings }\end{array}$} & \multicolumn{3}{|c|}{$\begin{array}{l}\text { Rotation Sums of } \\
\text { Squared Loadings }\end{array}$} \\
\hline $\begin{array}{c}\text { po } \\
\text { ne } \\
\text { nt }\end{array}$ & Total & $\begin{array}{c}\% \text { of } \\
\text { Vari } \\
\text { ance }\end{array}$ & $\begin{array}{l}\text { Cum } \\
\text { ulati } \\
\text { ve } \%\end{array}$ & Total & $\begin{array}{r}\% \text { of } \\
\text { Varia } \\
\text { nce }\end{array}$ & $\begin{array}{r}\text { Cum } \\
\text { ulativ } \\
\text { e } \%\end{array}$ & $\begin{array}{l}\text { Tot } \\
\text { al }\end{array}$ & $\begin{array}{c}\% \text { of } \\
\text { Vari } \\
\text { ance }\end{array}$ & $\begin{array}{l}\text { Cum } \\
\text { ulativ } \\
\text { e } \%\end{array}$ \\
\hline 1 & $\begin{array}{c}4.81 \\
3\end{array}$ & $\begin{array}{c}30.0 \\
81\end{array}$ & $\begin{array}{c}30.0 \\
81\end{array}$ & 4.813 & $\begin{array}{l}30.08 \\
1\end{array}$ & $\begin{array}{r}30.08 \\
1\end{array}$ & $\begin{array}{r}2.6 \\
17\end{array}$ & $\begin{array}{r}16.3 \\
53 \\
\end{array}$ & $\begin{array}{r}16.35 \\
3 \\
\end{array}$ \\
\hline 2 & $\begin{array}{l}1.79 \\
9\end{array}$ & $\begin{array}{l}11.2 \\
42\end{array}$ & $\begin{array}{l}41.3 \\
22\end{array}$ & 1.799 & $\begin{array}{l}11.24 \\
2\end{array}$ & $\begin{array}{r}41.32 \\
2\end{array}$ & $\begin{array}{l}2.3 \\
63\end{array}$ & $\begin{array}{r}14.7 \\
66\end{array}$ & $\begin{array}{r}31.11 \\
9\end{array}$ \\
\hline 3 & $\frac{1.40}{5}$ & $\begin{array}{l}8.78 \\
0\end{array}$ & $\begin{array}{l}50.1 \\
02\end{array}$ & 1.405 & 8.780 & $\begin{array}{r}50.10 \\
2\end{array}$ & $\begin{array}{l}2.1 \\
63\end{array}$ & $\begin{array}{r}13.5 \\
18\end{array}$ & $\begin{array}{r}44.63 \\
7\end{array}$ \\
\hline 4 & $\begin{array}{l}1.06 \\
8\end{array}$ & $\begin{array}{l}6.67 \\
8\end{array}$ & $\begin{array}{c}56.7 \\
80\end{array}$ & 1.068 & 6.678 & $\begin{array}{r}56.78 \\
0\end{array}$ & 1.943 & $\begin{array}{r}12.1 \\
43\end{array}$ & $\begin{array}{r}56.78 \\
0\end{array}$ \\
\hline 5 & .965 & $\begin{array}{l}6.02 \\
9\end{array}$ & $\begin{array}{l}62.8 \\
09\end{array}$ & & & & & & \\
\hline 6 & .842 & $\begin{array}{l}5.26 \\
4\end{array}$ & $\begin{array}{l}68.0 \\
74\end{array}$ & & & & & & \\
\hline 7 & .749 & $\begin{array}{l}4.68 \\
1\end{array}$ & $\begin{array}{l}72.7 \\
55\end{array}$ & & & & & & \\
\hline 8 & .689 & $\begin{array}{l}4.30 \\
9\end{array}$ & $\begin{array}{l}77.0 \\
63\end{array}$ & & & & & & \\
\hline 9 & .631 & $\begin{array}{l}3.94 \\
4\end{array}$ & $\begin{array}{l}81.0 \\
08\end{array}$ & & & & & & \\
\hline 10 & .605 & $\begin{array}{l}3.78 \\
0\end{array}$ & $\begin{array}{l}84.7 \\
87\end{array}$ & & & & & & \\
\hline 11 & .491 & $\begin{array}{l}3.06 \\
7\end{array}$ & $\begin{array}{l}87.8 \\
54\end{array}$ & & & & & & \\
\hline 12 & .457 & $\begin{array}{l}2.85 \\
9\end{array}$ & $\begin{array}{l}90.7 \\
13\end{array}$ & & & & & & \\
\hline 13 & .448 & $\begin{array}{l}2.79 \\
9\end{array}$ & $\begin{array}{l}93.5 \\
12\end{array}$ & & & & & & \\
\hline 14 & .427 & $\begin{array}{l}2.67 \\
1\end{array}$ & $\begin{array}{l}96.1 \\
83\end{array}$ & & & & & & \\
\hline 15 & .374 & $\begin{array}{l}2.33 \\
5\end{array}$ & $\begin{array}{l}98.5 \\
18\end{array}$ & & & & & & \\
\hline 16 & .237 & $\begin{array}{l}1.48 \\
2\end{array}$ & $\begin{array}{l}100 . \\
000\end{array}$ & & & & & & \\
\hline
\end{tabular}

Sumber : Data Primer, dianalisis 2019.

Pada Tabel Total Variance Explained, ditunjukan bahwa varian dari faktor pertama mempunyai nilai 4,813 dari 16 faktor yang ada. Faktor yang pertama ini menjelaskan bahwa $30,081 \%$ dari total varian yang ada; faktor yang kedua menjelaskan bahwa $11,242 \%$ dari total varian yang ada; faktor yang ketiga menjelaskan bahwa 8,780\% dari total varian yang ada; faktor yang keempat menjelaskan bahwa $6.678 \%$ dari total varian yang ada.Total varian yang dapat dijelaskan oleh keempat faktor tersebut terhadap variabel yang digunakan adalah $56.780 \%$, sisanya yaitu $100 \%-56.780 \%$ varian yang tidak dapat dijelaskan oleh variabel tersebut.

Nilai eigenvalues yang $<1$ dapat dikatakan bahwa variannya tidak dapat menjelaskan dari varian yang dibutuhkan. Melihat hasil analisis di faktor yang dapat disusun dalam variabel atau butir kuisioner ini adalah 4 faktor.

\section{Matriks Faktor Sebelum Dirotasi} Untuk menentukan indikator mana yang termasuk ke dalam faktor yang terbentuk, dapat dilihat pada tabel Component Matrix berikut:

Tabel 7

Matriks Faktor Sebelum Dirotasi

\begin{tabular}{|l|r|r|r|r|}
\hline Component Matrix & \multicolumn{4}{|c|}{ Component } \\
\cline { 2 - 5 } & 1 & 2 & \multicolumn{1}{|c|}{3} & \multicolumn{1}{c|}{4} \\
\hline $\begin{array}{l}\text { Melepaskan diri dari rutinitas } \\
\text { pekerjaan }\end{array}$ & .585 & .559 & .031 & .264 \\
melepaskan kegelisahan & .588 & .518 & -.129 & .342 \\
menyegarkan pikiran & .501 & .551 & .100 & .016 \\
mencari ketenangan & .377 & .442 & -.188 & .092 \\
$\begin{array}{l}\text { ingin menikmati aktivitas } \\
\text { yang menyenangkan }\end{array}$ & .567 & .101 & -.236 & -.436 \\
$\begin{array}{l}\text { Melakukan kunjungan untuk } \\
\text { mendapatkan keberkahan }\end{array}$ & .553 & .066 & -.296 & -.284 \\
$\begin{array}{l}\text { mempererat hubungan } \\
\text { keakraban } \\
\text { menjalin silaturahmi }\end{array}$ & .565 & .006 & -.288 & -.508 \\
$\begin{array}{l}\text { Berkunjung ke kawasan } \\
\text { wisata untuk meningkatkan } \\
\text { status social }\end{array}$ & .564 & -.049 & .601 & -.166 \\
\hline
\end{tabular}


Tabel 7 (Lanjutan)

Matriks Faktor Sebelum Dirotasi

\begin{tabular}{|l|c|c|c|c|}
\hline Component Matrix & \multicolumn{4}{|c|}{ Component } \\
\cline { 2 - 5 } & 1 & 2 & \multicolumn{1}{|c|}{3} & 4 \\
\hline $\begin{array}{l}\text { interaksi dengan masyarakat } \\
\text { sekitar }\end{array}$ & .631 & -.159 & .328 & -.235 \\
mencari kenyamanan & .482 & -.101 & .121 & -.134 \\
$\begin{array}{l}\text { Keinginan untuk menambah } \\
\text { pengetahuan baru }\end{array}$ & .568 & -.362 & .076 & .066 \\
$\begin{array}{l}\text { Memiliki tujuan berkunjung } \\
\text { untuk berdoa }\end{array}$ & .550 & -.366 & -.237 & .200 \\
$\begin{array}{l}\text { Berkunjung untuk mengetahui } \\
\text { kegiatan wisatawan }\end{array}$ & .561 & -.355 & -.254 & .130 \\
$\begin{array}{l}\text { keinginan untuk melakukan } \\
\text { perjalanan wisata }\end{array}$ & .639 & -.298 & -.254 & .252 \\
Adanya keyakinan dalam diri & .483 & -.399 & .007 & .371 \\
\hline
\end{tabular}

Extraction Method: Principal Component

Analysis.

a. 4 components extracted.

Tabel

Component Matrix menunjukkan kontribusi enambelas indikator tersebut pada tujuh faktor yang terbentuk. Factor loadings yaitu besarnya korelasi antara masing-masing variabel dengan Faktor 1, Faktor 2, Faktor 3, Faktor 4.

Proses penentuan indikator yang akan masuk ke faktor terbentuk, dilakukan dengan melakukan perbandingan dengan besar korelasi pada setiap baris. Sebagai contoh indikator melepaskan diri dari aktivitas pekerjaan masuk ke faktor 1, karena faktor loading indikator ini dengan faktor 1 dianggap sangat signifikan $(0,585)$, begitu juga dengan variabel-variabel yang lainnya.

Agar semakin jelas perbedaan sebuah indikator, akan dimasukkan pada faktor 1 , faktor 2, faktor 3, faktor 4, maka perlu dilakukan proses rotasi.Berikut disajikan matriks faktor setelah rotasi yang telah dikeolpokan berdasarkan faktor yang terbentuk.

\section{Matriks Faktor Setelah Dirotasi}

Matriks faktor ini bertujuan untuk mempermudah interpretasi dalam menentukan indikator-indikator mana saja yang tercantum dalam suatu faktor. Maka dilakukan uji kelayakan dengan menggunakan Component Matrix dengan metode rotasi yang akan memperjelas posisi sebuah indikator pada sebuah faktor seperti pada tabel berikut:

Tabel 8

Rotated Component Matrix ${ }^{\mathrm{a}}$

\begin{tabular}{|c|c|c|c|c|}
\hline & \multicolumn{4}{|c|}{ Component } \\
\hline & 1 & 2 & 3 & 4 \\
\hline $\begin{array}{l}\text { Melepaskan diri dari rutinitas } \\
\text { pekerjaan }\end{array}$ & .113 & .815 & .205 & .077 \\
\hline melepaskan kegelisahan & .224 & .828 & .060 & .085 \\
\hline menyegarkan pikiran & -.068 & .669 & .268 & .200 \\
\hline mencari ketenangan & .048 & .580 & -.039 & .203 \\
\hline $\begin{array}{c}\text { ingin menikmati aktivitas yang } \\
\text { menyenangkan }\end{array}$ & .124 & .206 & .144 & .706 \\
\hline $\begin{array}{l}\text { Melakukan kunjungan untuk } \\
\text { mendapatkan keberkahan }\end{array}$ & .227 & .234 & .062 & .607 \\
\hline $\begin{array}{l}\text { mempererat hubungan } \\
\text { keakraban }\end{array}$ & .162 & .107 & .121 & .779 \\
\hline menjalin silaturahmi & .092 & .109 & .820 & .132 \\
\hline $\begin{array}{c}\text { Berkunjung ke kawasan wisata } \\
\text { untuk meningkatkan status } \\
\text { social }\end{array}$ & 139 & .202 & .773 & -.095 \\
\hline $\begin{array}{l}\text { interaksi dengan masyarakat } \\
\text { sekitar }\end{array}$ & .244 & .053 & .644 & .330 \\
\hline mencari kenyamanan & .235 & .086 & .371 & .273 \\
\hline $\begin{array}{l}\text { Keinginan untuk menambah } \\
\text { pengetahuan baru }\end{array}$ & .550 & .000 & .366 & .166 \\
\hline $\begin{array}{c}\text { Memiliki tujuan berkunjung } \\
\text { untuk berdoa }\end{array}$ & 699 & .068 & .069 & .188 \\
\hline $\begin{array}{l}\text { Berkunjung untuk mengetahui } \\
\text { kegiatan wisatawan }\end{array}$ & .670 & .057 & .071 & .256 \\
\hline $\begin{array}{l}\text { keinginan untuk melakukan } \\
\text { perjalanan wisata }\end{array}$ & .738 & .184 & .080 & .199 \\
\hline Adanya keyakinan dalam diri & .689 & .051 & .216 & -.081 \\
\hline
\end{tabular}


Extraction Method: Principal Component

Analysis.

Rotation Method: Varimax with Kaiser

Normalization.

Rotation converged in 6 iterations.

Sumber : Pengujian Analisis Data

SPSS, 2019

Sekalipun dari 16 indikator telah terbentuk faktor-faktor, namun perlu dilakukan rotasi untuk memperjelas variabel-variabel mana yang masuk ke dalam tiap-tiap faktor. Banyak sekali faktor loading yang berubah setelah mengalami rotasi menjadi lebih kecil atau lebih besar. Hasil rotasi yang disampaikan pada tabel diatas dijelaskan sebagai berikut:

1. Indikator keinginan untuk menambah pengetahuan baru: indikator ini masuk ke faktor 1 , karena faktor loading indikator ini dengan faktor 1 dianggap sangat signifikan $(0,550)$.

2. Indikator memiliki tujuan untuk berdoa: indikator ini masuk ke faktor 1, karena faktor loading indikator ini dengan faktor 1 dianggap sangat signifikan $(0,699)$.

3. Indikator berkunjung untuk mengetahui kegiatan wisatawan: indikator ini masuk ke faktor 1, karena faktor loading indikator ini dengan faktor 1 dianggap sangat signifikan $(0,670)$.

4. Indikator keinginan untuk melakukan perjalanan wisata : indikator ini masuk ke faktor 1 , karena faktor loading indikator ini dengan faktor 1 dianggap sangat signifikan $(0,670)$.

5. Indikator adanya keyakinan dalam diri: indikator ini masuk ke faktor 1 , karena faktor loading indikator ini dengan faktor 1 dianggap sangat signifikan $(0,689)$.

6. Indikator melepaskan diri dari rutinitas pekerjaan : indikator ini masuk ke faktor 2, karena faktor loading indikator ini dengan faktor 2 dianggap sangat signifikan $(0,113)$.

7. Indikator melepaskan kegelisahan: indikator ini masuk ke faktor 2 , karena faktor loading indikator ini dengan faktor 2 dianggap sangat signifikan $(0,068)$.

8. Indikator menyegarkan pikiran: indikator ini masuk ke faktor 2 , karena faktor loading indikator ini dengan faktor 2 dianggap sangat signifikan $(0,914)$.

9. Indikator mencari ketenangan: indikator ini masuk ke faktor 2, karena faktor loading indikator ini dengan faktor 2 dianggap sangat signifikan $(0,048)$.

10. Indikator menjalin silaturahmi: indikator ini masuk ke faktor 3, karena faktor loading indikator ini dengan faktor 3 dianggap sangat signifikan $(0,092)$.

11. Indikator berkunjung ke kawasan wisata untuk meningkatkan status sosial indikator ini masuk ke faktor 3 , karena faktor loading indikator ini dengan faktor 3 dianggap sangat signifikan $(0,190)$.

12. Indikator interaksi dengan masyarakat sekitar : indikator ini masuk ke faktor 3, karena faktor loading indikator ini dengan faktor 3 dianggap sangat signifikan $(0,244)$.

13. Indikator mencari kenyamanan : indikator ini masuk ke faktor 3, karena faktor loading indikator ini dengan faktor 3 dianggap sangat signifikan $(0,235)$.

14. Indikator ingin menikmati aktivitas yang menyenangkan: indikator ini masuk ke faktor 4, karena faktor loading indikator ini dengan faktor 4 dianggap sangat signifikan $(0,124)$.

15. Indikator melakukan kunjungan untuk mendapatkan keberkahan: indikator ini masuk ke faktor 4, karena faktor loading indikator ini dengan faktor 4 dianggap sangat signifikan $(0,227)$.

16. Indikator mempererat hubungan keakraban: indikator ini masuk ke faktor 4, karena faktor loading indikator ini dengan faktor 4 dianggap sangat signifikan $(0,162)$. 


\section{Pembobotan Faktor}

Bobot faktor adalah ukuran yang menyatakan representasi suatu indikator oleh masing-masing faktor. Faktor dengan bobot faktor tinggi untuk suatu indikator menunjukkan tingginya hubungan faktor itu dengan indikatornya. Hasil indikator yang telah dirotasi menjelaskan indikatorindikator mana saja yang termasuk atau dikategorikan ke dalam faktor 1, faktor 2, faktor 3 , faktor 4 , , secara ringkas tertera dalam tabel berikut:

Tabel 9

Hasil Penelitian Rotated Component Matrix

\begin{tabular}{|c|c|c|c|c|c|}
\hline \multirow[t]{2}{*}{ No. } & \multirow[t]{2}{*}{ Indikator } & \multicolumn{4}{|c|}{ Faktor } \\
\hline & & 1 & 2 & 3 & 4 \\
\hline 1 & $\begin{array}{l}\text { Melepaskan diri } \\
\text { dari rutinitas } \\
\text { pekerjaan }\end{array}$ & & 0,815 & & \\
\hline 2 & $\begin{array}{l}\text { Melepaskan } \\
\text { kegelisahan }\end{array}$ & & 0,828 & & \\
\hline 3 & $\begin{array}{l}\text { Menyegarkan } \\
\text { pikiran }\end{array}$ & & 0,669 & & \\
\hline 4 & $\begin{array}{c}\text { Mencari } \\
\text { ketenangan }\end{array}$ & & 0,580 & & \\
\hline 5 & $\begin{array}{l}\text { Ingin menikmati } \\
\text { aktivitas yang } \\
\text { menyenangkan }\end{array}$ & & & & 0,706 \\
\hline 6 & $\begin{array}{c}\text { Melakukan } \\
\text { kunjungan untuk } \\
\text { mendapatkan } \\
\text { keberkahan }\end{array}$ & & & & 0,607 \\
\hline 7 & $\begin{array}{l}\text { Mempererat } \\
\text { hubungan } \\
\text { keakraban }\end{array}$ & & & & 0,779 \\
\hline 8 & $\begin{array}{l}\text { Menjalin } \\
\text { silaturahmi }\end{array}$ & & & 0,820 & \\
\hline 9 & $\begin{array}{c}\text { Berkunjung ke } \\
\text { kawasan wisata } \\
\text { untuk } \\
\text { meningkatkan } \\
\text { status social }\end{array}$ & & & 0,773 & \\
\hline 10 & $\begin{array}{c}\text { Interaksi dengan } \\
\text { masyarakat } \\
\text { sekitar }\end{array}$ & & & 0,644 & \\
\hline
\end{tabular}

Tabel 9 (Lanjutan)

Hasil Penelitian Rotated Component

Matrix

\begin{tabular}{|c|c|c|c|c|c|}
\hline \multirow{2}{*}{ No. } & \multirow{2}{*}{ Indikator } & \multicolumn{4}{|c|}{ Faktor } \\
\hline & & 1 & 2 & 3 & 4 \\
\hline 11 & $\begin{array}{c}\text { Mencari } \\
\text { kenyamanan }\end{array}$ & & & 0,371 & \\
\hline 12 & $\begin{array}{c}\text { Keinginan untuk } \\
\text { menambah } \\
\text { pengetahuan } \\
\text { baru }\end{array}$ & 0,550 & & & \\
\hline 13 & $\begin{array}{c}\text { Memiliki tujuan } \\
\text { berkunjung } \\
\text { untuk berdoa }\end{array}$ & 0,699 & & & \\
\hline 14 & $\begin{array}{l}\text { Berkunjung } \\
\text { untuk } \\
\text { mengetahui } \\
\text { kegiatan } \\
\text { wisatawan }\end{array}$ & 0,670 & & & \\
\hline 15 & $\begin{array}{l}\text { keinginan untuk } \\
\text { melakukan } \\
\text { perjalanan } \\
\text { wisata }\end{array}$ & 0,738 & & & \\
\hline 16 & $\begin{array}{c}\text { Adanya } \\
\text { keyakinan dalam } \\
\text { diri }\end{array}$ & 0,689 & & & \\
\hline
\end{tabular}

Sumber: Data diolah, 2019.

Berdasarkan tabel Hasil penelitian component matrix, maka pemberian nama faktor - faktor yang berpengaruh dapat dilakukan sebagai berikut :

\section{Tabel 10}

Penamaan Faktor Yang Terbentuk

\begin{tabular}{|c|c|c|c|c|}
\hline Faktor & $\begin{array}{c}\text { Nama } \\
\text { Faktor }\end{array}$ & Indikator & $\begin{array}{l}\text { Nilai } \\
\text { Faktor }\end{array}$ & $\begin{array}{c}\% \text { of } \\
\text { Varia } \\
\text { nce }\end{array}$ \\
\hline 1. & $\begin{array}{c}\text { Keingina } \\
\mathrm{n} \text { untuk } \\
\text { menamba } \\
\mathrm{h} \\
\text { pengetahu } \\
\text { an baru }\end{array}$ & $\begin{array}{c}\text { Keinginan } \\
\text { untuk } \\
\text { menambah } \\
\text { pengetahuan } \\
\text { baru } \\
\text { Memiliki } \\
\text { tujuan } \\
\text { berkunjung } \\
\text { untuk berdoa }\end{array}$ & 0,550 & $\begin{array}{c}30.08 \\
1\end{array}$ \\
\hline
\end{tabular}


Tabel 10 (Lanjutan)

Penamaan Faktor Yang Terbentuk



Dari ke empat faktor baru yang terbentuk dapat ditentukan nama untuk faktor dengan melihat indikator-indikator pembentuknya dengan memperhatikan kesimpulan dari nama indikator yang termasuk ke dalam faktor terbentuk tersebut.

1. Faktor 1 berdasarkan keinginan untuk menambah pengetahuan baru, memiliki tujuan berkunjung untuk berdoa, berkunjung untuk mengetahui kegiatan wisatawan,

keinginan untuk melakukan perjalanan wisata, adanya keyakinan dalam diri.

2. Faktor 2 berdasarkan melepaskan diri dari rutinitas pekerjaan, melepaskan kegelisahan, menyegarkan pikiran,mencari ketenangan.

3. Faktor 3 berdasarkan menjalin silaturahmi, berkunjung ke kawasan wisata untuk meningkatkan status sosial,interaksi dengan masyarakat sekitar, mencari kenyamanan.

4. Faktor 4 berdasarkan ingin menikmati aktivitas yang menyenangkan, melakukan kunjungan untuk mendapatkan keberkahan, mempererat hubungan keakraban.

Dapat disimpulkan bahwa 4 faktor inilah yang sangat berpengaruh terhadap keputusan berkunung pada makam syekh Quro Karawang sebagai responden dalam penelitian ini.

\subsubsection{Faktor-Faktor Dominan yang Mempengaruhi keputusan berkunjung}

\subsubsection{Rentang Skala}

Dilihat dari rata-rata terbesar diantara semua dimensi/faktor hasil analisis yang terdapat pada Tabel 4.15 Rekapitulasi Indikator Variabel Keputusan berkunjung, dapat diperoleh indikator dengan skor terbesar yaitu Educaational Opportunity dengan skor 1.188. Artinya, faktor yang dominan mempengaruhi keputusan berkunjung berdasarkan rentang skala yaitu educational opportunity.

\subsubsection{Analisis Faktor}

Berdasarkan Tabel Total Variance Explained dan Tabel 4.22 Penamaan Faktor, terdapat faktor dengan nilai eigenvalue terbesar yaitu faktor keinginan untuk 
menambah pengetahuan baru dengan nilai eigenvalue sebesar 30.081. Artinya, faktor keinginan untuk menambah pengetahuan baru adalah faktor dominan yang mempengaruhi keputusan berkunjung pada wisata religi Makam Syekh Quro Karawang.

\subsection{Pembahasan}

Berdasarkan hasil pengujian dari metode deskriptif dan analisis faktor mengenai variabel keputusan berkunjung dalam penelitian ini dapat diuraikan sebagai berikut:

\section{Faktor-Faktor yang Mempengaruhi keputusan berkunjung}

\section{a. Rentang Skala}

Keputusan berkunjung wisatawan dalam mengunjungi lokasi wisata religi makam syekh Quro Karawang dari 16 indikator yang berada pada rentang skala 1.043,9 - 1.289,5 dengan kriteria setuju, artinya keputusan berkunjung wisatawan dalam mengunjungi Makam Syekh Quro dinilai baik dan dari 16 butir pertanyaan atau indikator yaitu exscape, relaxation, play, strethening family bonds, prestige, social interaction, romance, educational opportunity, self-fullfillment, dan wishfull-fillment mempengaruhi keputusan berkunjung wisatawan di Makam Syekh Quro Karawang berdasarkan rentang skala. Dari hasil rekapitulasi terdapat indikator dengan skor terendah yaitu melepaskan diri dari rutinitas pekerjaan dengan skor 1.083. Hal ini berarti responden masih ragu dengan melepaskan diri dari rutinitas pekerjaan merupakan faktor wisatawan untuk berkunjung ke Makam syekh Quro Karawang .

Faktanya memang wisata lokasi wisata religi tersebut mempunyai image religious dan pengunjung yang datang ke area lokasi mempunyai niat/tujuan yang telah ditetapkan sebelumnya misalnya: berziarah/berdoa bersama sama. sehingga kurang cocok jika wisatawan yang datang ke lokasi tersebut karena merasa jenuh atau bosan pada rutinitas sehari harinya.

\section{b. Analisis Faktor}

Berdasarkan dari hasil analisis dan didapat hasil analisis faktor dengan memperhatikan nilai eigenvalues yang membentuk 4 faktor baru yang kemudian diberi nama berdasarkan nama baru yang dapat mewakili variabel-variabel yang menjadi anggotanya. Faktor-faktor baru ini pula dapat disimpulkan sebagai faktor-faktor yang mempengaruhi minat berkunjung wisatawan dalam mengunjungi Makam Syekh Quro Karawang berdasarkan analisis faktor. Berikut penamaan untuk masing-masing faktor yang terbentuk:

1) Keinginan untuk menambah pengetahuan baru

Keinginan untuk menambah pengetahuan dan memiliki tujuan berkunjung untuk berdoa menjadi pertimbangan wisatawan karena masyarakat yang berkunjung ke lokasi wisata selain tujuannya untuk mengetahui lokasi tersebut, juga untuk mendapatkan tambahan pengetahuan dan pemahaman mengenai berbagai fenomena alam dan budaya yang terjadi disekitar lokasi. Dan akan berpengaruh terhadap keputusan wisatawan untuk mengunjungi lokasi wisata tersebut,seperti dikutip dari hasil penelitian yang dilakukan Dina Amalia, (2017).indikator yang termasuk dalam faktor keinginan untuk menambah pengetahuan baru yaitu karakteristik wisatawan dan manfaat perjalanan wisata.

\section{2) Melepaskan diri dari} rutinitas pekerjaan

Faktor Melepaskan diri dari rutinitas pekerjaan, melepaskan kegelisahan, menyegarkan pikiran, dan mencari ketenangan. Hal ini dikarenakan wisatawan Ingin melepaskan diri dari lingkungan yang dirasakan menjenuhkan, atau kejenuhan dari pekerjaan seharihari. Yang biasanya dengan melakukan perjalanan wisata 
mereka akan merasa senang dan lupa akan kesibukannya yang dirasa cukup menjenuhkan.(Pitana dan Gayatri 2011:26).

\section{3) Menjalin silaturahmi}

Menjalin silaturahmi, berkunjung ke kawasan wisata untuk meningkatkan status social, interaksi dengan masyarakat sekitar dan mencari kenyamanan. Hal ini dikarenakan banyak cara dalam menjalin silaturahmi dan mempeerat hubungan keakraban baik dengan kelurga ataupun dengan kelompok lainnya misalnya menggelar acara gathering merupakan salah satunya. Bahkan sekarang ini acara gathering sudah familiar di banyak kelompok masyarakat. wisata relligi makam syekh quro Karawang pun menjadi pilihan masyarakat untuk menjalin silaturahmi baik diantara sesama pengunjung atau warga sekitar.(Pitana dan Gayatri 2011:26).

4) Menikmati aktivitas yang menyenangkan

Ingin menikmati aktivitas yang menyenangkan, melakukan kunjungan untuk mendapatkan keberkahan, mempererat hubungan keakraban. Hal tersebut dikarenakan wisatawan ingin Mengisi waktu senggang atau untuk bersenang-senang, berlibur, untuk alasan kesehatan, studi, keluarga, dan sebagainya .

Hasil penelitian yang dilakukan oleh Sukmawati Nur Salamah (2018), dengan judul “ Faktorfaktor yang mempengaruhi keputusan wisatawan datang ke objek wisata Religi (studi kasus pada Makam Sunan Gunung Jati Cirebon Jawa Barat)" Hasil dari penelitian tersebut berbeda dimana pada penelitian Sukmawati Nur Salamah di dapatkan hasil bahwa faktor yang mempengaruhi keputusan wisatawan berkunjung yaitu : 1. Pengelolaan, 2 . hubungan pengelola dengan pelaku pariwisata dan 3. Keinginan untuk bersilaturahmi/ziarah di lokasi sekitar.

2. Faktor-Faktor Dominan yang Mempengaruhi keputusan berkunjung

\section{a. Rentang Skala}

Dari 16 butir pertanyaan atau indikator yaitu exscape, relaxation, play, strethening family bonds, prestige, social interaction, romance, educational opportunity, self-fullfillment, dan wishfull-fillment indikator yang memperoleh skor terbesar yaitu Educaational Opportunity dengan skor 1.188. Artinya, faktor dominan yang mempengaruhi keputusan berkunjung berdasarkan rentang skala yaitu educational opportunity. Dibuktikan dengan survei lapangan yang dilakukan, bahwa educational opportunity dapat memberikan informasi baru mengenai lokasi wisata, ataupun pengalaman yang sebelumnya belum alami oleh wisatawan.

\section{b. Analisis Faktor}

Dari ke empat faktor yaitu keingianan untuk mengetahui pengetahuan baru, melepaskan diri dari rutinitas pekerjaan, menjalin silaturahmi dan menikmati aktivitas yang menyenangkan, yang memberikan pengaruh dominan terhadap keputusan berkunjung yaitu faktor keinginan untuk menambah pengetahuan baru. Faktor ini merupakan faktor yang memiliki pengaruh terbesar dengan eigenvalue 4,813 dan mampu menjelaskan variance total sebesar $30.081 \%$.

\section{SIMPULAN DAN SARAN}

\subsection{Simpulan}

Berdasarkan penelitian yang dilakukan maka simpulan yang dapat diambil mengenai Analisis Faktor - Faktor Yang Mempengaruhi Keputusan berkunjung Pada Makam Syekh Quro Karawang adalah sebagai berikut :

1. Terdapat 4 kelompok faktor yang mempengaruhi wisatawan untuk berkunjung pada makam Syekh Quro 
Karawang yaitu faktor Keinginan untuk menambah pengetahuan baru, melepaskan diri dari rutinitas pekerjaan, menjalin silaturahmi dan ingin menikmati aktivitas yang menyenangkan. Faktor - faktor yang didapatkan pada penelitian ini mempengaruhi wisatawan untuk berkunjung pada Makam Syekh Quro Karawang. secara keseluruhan berada pada kriteria "setuju" karena memiliki persentase pengaruh sebesar $56,781 \%$. Hal ini berarti semua faktor yang terbentuk dianggap cukup penting oleh pengunjung Makam Syekh Quro Karawang.

2. Faktor paling dominan dalam membentuk keputusan berkunjung pada Makam Syekh Quro Karawang adalah factor keinginan untuk menambah pengetahuan baru , dimana faktor tersebut merupakan faktor yang memiliki pengaruh terbesar dengan eigenvalues sebesar 4,813 dan mampu menjelaskan varianve total sebesar $30,081 \%$. Artinya faktor keinginan untuk menambah pengetahuan baru mempengaruhi sebesar 30,081\% keputusan berkunjung pada Makam Syekh Quro atau dengan kata lain faktor keinginan untuk menambah pengetahuan baru mempengaruhi sebesar $56,781 \%$ lebih besar dari kedua faktor lainnya.

\subsection{Saran}

Berdasarkan hasil penelitian dan pembahasan hasil analisa keputusan wisatawan dalam mengunjungi wisata religi makam syekh quro karawang yang telah dilakukan. maka penulis memberikan saransaran yang dapat dipertimbangkan oleh pengelola wisata religi makam syekh quro karawang khususnya untuk mengetahui faktor-faktor apa saja yang dapat mempengaruhi keputusan wisatawan dalam berkunjung ke wisata religi makam syekh quro karawang. Sebagai berikut :

1. Letak geografis atau jauhnya lokasi dari pusat kota karawang sehingga masih jarang transportasi umum untuk menuju lokasi makam syekh quro karawang. Maka dari itu, pihak pengelola perlu menyediakan adanya trasportasi umum yang menuju ke akses lokasi.

2. Pengelola lokasi wisata religi makam syekh quro karawang harus memperbanyak/memberikan informasi tentang wisata agar masyarakat , baik dari daerah karawang maupun luar karawang lebih mengenal lokasi wisata tersebut. Selain itu, pengelola harus bisa memanfaatkan media sosial dan internet untuk pengembangan informasi mengenai wisata religi makam syekh quro karawang tersebut.

\subsubsection{Saran Bagi Peneliti Selanjutnya}

Sehubungan dengan penelitian yang telah penulis lakukan, ada beberapa hal yang perlu diperhatikan oleh peneliti selanjutnya:

1. Peneliti selanjutnya diharapkan meneliti faktor- faktor lain yang belum diteliti dalam mempengaruhi keputusan berkunjung. Jika peneliti selanjutnya ingin meneliti tentang wisata religi, diharapkan peneliti selanjutnya bisa meneliti tentang faktor mengenai gaya hidup, lokasi, ataupun fasilitas disekitar lokasi tersebut.

2. Peneliti selanjutnya diharapkan untuk mempersiapkan instrument yang lebih jelas dan detail sehingga responden lebih mudah untuk menyampaikan pendapatnya.

3. Peneliti selanjutnya diharapkan meneliti objek penelitian yang lain. Mengingat masih banyak tempat wisata yang ada di Karawang

\section{DAFTAR PUSTAKA}

\section{Buku :}

A.A Anwar Prabu Mangkunegara (2012). Manajemen Sumber Daya Manusia. Bandung: PT. Remaja Rosdakarya.

Ali, Hasan . 2013. Marketing dan KasusKasus Pilihan. Yogyakarta. CAPS (Center For Academic Publishing Service) 
Buchari Alma, dan Saladin, Djaslim. 2010. Manajemen Pemasaran : Ringkasan Praktis, Teori, Aplikasi Dan Tanya Jawab. Bandung : CV. Linda Karya

Buchari Alma, 2011, ManajemenPemasaran dan Pemasaran Jasa. Alfabeta, Bandung

Dr. I Gusti Bagus Rai Utama,M.A 2017. Pemasaran Pariwisata. CV .ANDI OFFSET Yogyakarta 55281.

David, L. Loudon dan Albert J. Della Bitta. 2012. Consumer Behaviour. Third Edition. New York, McGraw-Hill Book Company

E.Sutisna 2009. Ikhtisar sejarah singkat Syekh Qurotul'ain.

MAHDITA,Karawang.

George R terry 2011, principle of management .Alexander hamlton institude ,New york.

Ghozali, Imam. 2013. Aplikasi Analisis Multivariate dengan Program IBM SPSS 21 Update PLS Regresi. Semarang: Badan Penerbit Universitas Diponegoro.

Hasibuan, Malayu S.P., 2011. Manajemen Sumber Daya Manusia. Bumi Aksara, Jakarta

Hardius dan Nurdin. 2013. Aplikasi Teknik Multivariate untuk Riset Pemasaran. Depok (ID) : PT Rajagrafindo Persada.

I Ketut Suwena \& I Gusti Ngurah Wdyaatmaja (2017). Pengetahuan Dasar Ilmu Pariwsata. Larasan . Denpasar,Bali 80116

Kotler, Phillip. 2011. Manajemen Pemasaran Jilid II (edisi Bahasa Indonesia). Jakarta: PT Prenhalindo Indonesia. Kotler, Phillip. 2005. Manajemen Pemasaran. Jilid 1. Jakarta: PT Indeks Kelompok Gramedia.

Kotler and Kaller.2011 Manajemen Pemasaran Jilid I.Jakarta : Erlangga
Kotler,phillip and Gery Amstrong. 2015 prinsip- prinsip pemasaran edisi 13 . Jilid 1 Jakarta: erlangga

Oka A. Yoeti. 2017. Pengantar Ilmu Pariwisata. Angkasa. Bandung

Pendit,Nyoman S.1990. Ilmu pariwisata sebuah pengantar perdana. Jakarata ,pradnya paramita 333.4791

Pitana, I Gede \& Gayatri, Putu G. (2011). Sosiologi Pariwisata. Yogyakarta : CV Andi Offset.

Robbins, P. Stephen dan Mary Coulter. 2012. Manajemen, diterjemahkan oleh Bob Sabran, Wibi Hardani. Erlangga:Jakarta

Schiffman, L.G., dan Kanuk, L.L, 2015, Perilaku Konsumen, dialih bahasakan oleh Zulkifli Kasip, Edisi Ketujuh, Penerbit PT. Indexs.

Sugiyono. 2016. Metode Penelitian Kuantitatif, Kualitatif danR\&D. Bandung: PT Alfabet.

Suharyadi, Purwanto. 2009. Statistika Untuk Ekonomi dan Keuangan Modern. Jakarta: Salemba Empat

Supranto, J. 2011. Pengukuran Tingkat Kepuasan Pelanggan Untuk Menaikkan Pangsa Pasar, Cetakan keempat, Penerbit PT Rineka Cipta, Jakarta.

Suharno dan Yudi Sutarso. 2009. Marketing in practice. Yogyakarta : Graha Ilmu.

Sujarweni, Wiratna. 2015. SPSS Untuk Penelitian. Yogyakarta : Pustaka Baru Press

Tjiptono fandy, 2014. Pemasaran Jasa : Prinsip, Penerapan, Penelitian . Edisi Ketiga. Yogyakarta: Andi Offset.

Universtas sngaperbangsa Karawang 2017. Buku pedoman penyusunan skripsi edisi 2017

\section{Jurnal dan Skripsi :}

Aji Prasetyo (2016). Faktor- faktor yang Mempengaruhi Keputusan Wisatawan 
dalam Berkunjung ke Objek Wisata Waduk Gajah Mungkur Wonogiri.Skripsi. Universitas Sebelas Maret Surakarta.

Cony Maharani.P (2014). Pengaruh Brand Postitionng wonderful Indonesia Terhadap Keputusan Wisatawan Mancanegara Untuk Berkunjung ke Indonesia. Tourism and Hospitality Essentials (THE) journal, Vol. IV No. 1,2014-741

Dina Amalina (2017). Faktor yang Mempengaruhi Proses Pengambilan Keputusan Wisatawan Berkunjung ke Objek Wisata Religi Masjid Agung Islamic Centre Kabupaten Rokan Hulu. JOM FISIP Vol. 4 No. 2 - Oktober 2017

Desmalasari, A.H.G.Kusumah \& Sri Marhanah (2018). Analisis faktor motivasi wisatawan muda dalam mengunjungi destnasi wisata minat khusus. Journal of Indonesian Tourism, Hospitality and Recreation Volume 1, Nomor 2, Oktober 2018

Desi Handayani (2009). Analisis prilaku masyarakat terhadap keputusan mengunjungi destinasi wisata syariah di Sumatra barat. Sosial Budaya, Volume 14, Nomor 02, Desember 2017, pp. 200 $-207$

Fahmi Farhan (2016) .Analisis Faktor-faktor yang mempengaruhi keputusan wisatawan untuk mengunjungi wisata alam curug cigentis loji karawang. Skripsi. Universitas Singaperbangsa Karawang.

Irma Juni Sudaryanti,Erry Sukriah \& Rosita (2015). Analisis faktor-faktor yang mempengaruhi motvasi wisatawan dalam melakukan wisata Heritage di kawasan Braga kota Bandung. Jurnal Manajemen Resort \& Leisure Vol. 12, No. 1, April 2015

Liga Suryadana (2015). Faktor- faktor pengambilan wisatawan untuk berkunjung ke objek wisata istana siak sri indrapura kabupaten siak provinsi riau. Sosial Budaya, Volume 14, Nomor 06, Desember 2015, pp. $200-$ 207

M Akrom.K (2014). Analisis Faktor-Faktor yang mempengaruhi Keputusan Kunjungan Wisatawan di Pantai Cahaya,Weleri Kabupaten Kendal.Skripsi. Unversitas Diponegoro Semarang.

Ratih Hurriyati (2010). Pengaruh faktorfaktor lingkungan eksternal terhadap keputusan berkunjung wisatawan (Survei pada Wisatawan Museum Angkut Batu Jawa Timur). JurnalBisnis(JAB)|Vol.21No.1April20 15.

Sopiah (2013). Analisis Faktor- Faktor pendorong motivasi wisatawan nusantara terhadap keputusan berkunjung ke kebun raya Bogor (Survei Pada Wisatawan Nusantara yang Berkunjung ke Kebun Raya Bogor. Tourism and Hospitality Essentials (THE) Journal, Vol.II, No.1, $2012-246$

Sukmawati Nur Salamah (2018). Analisis Faktor- faktor yang mempengaruhi keputusan berkunjung wisatawan ( studi kasus pada Makam Sunan Gunung Jati Cirebon Jawa Barat). Universitas Gadjah Mada.

Tus Ria Nurmalasari (2016). Analisis Faktor yang Mempengaruhi Pengunjung Objek Wisata Kawah Ijen Banyuwangi. Sosial Budaya, Volume 14, Nomor 02, Desember 2017, pp. 200 - 207

Wibisono,Tamara,Lisa,Toly dan Agus Arianto (2014). Analisis Faktor-Faktor Yang Mempengaruhi Minat Wajib Pajak Dalam Penggunaan E-Filling Di Surabaya. Jurnal Tax \& Accounting Review, 4 (1): 1-15

\section{Internet :}

Dr.H. Dedi Taufik ,M.Si. 2010. Dinas Pariwisata dan Kebudayaan Provinsi Jawa Barat. 
http://www.disparbud.jabarprov.go.id/appli cations/frontend/index.php (di akses 12

Maret).

Dody Herlando. 2017. Badan Pusat Statistik Provinsi Jawa Barat. Di https://jabar.bps.go.id// (di akses pada 14 Maret).

Jihad Hayatul Falah. 2019. 27 Tempat wisata yang ada di Karawang di https://wisatalengkap.com/tempat-wisatadi-karawang/ (di akses pada 7 Maret).

Islam Cendekia. 2018. Syekh Quro Karawang: Karomah ,nasab ,keturunan dan silsilahnya.

https://www.islamcendekia.com/2018/09/sy ekh-quro-karawang-karomah-nasab-

keturunan-dan-silsilahnya.html (di akses pada 20 februari).

Jeffrey Wibisono V.2013. Motivasi Berwisata dan Faktor Penariknya. Di http://jeffreywibisono.com/motivasiberwisata-dan-faktor-penariknya/ (di akses pada 29 Maret).

Undang- Undang Republik Indonesia No 10 Tahun 2019. Tentang Kepariwisataan di https://www.ekowisata.org/uploads/files/U U 10 2009.pdf (di akses pada 18 Maret) 